\title{
IONOTROPIC AND METABOTROPIC GLUTAMATE RECEPTOR MEDIATION OF GLUCOCORTICOID-INDUCED APOPTOSIS IN HIPPOCAMPAL CELLS AND THE NEUROPROTECTIVE ROLE OF SYNAPTIC N-METHYL-D-ASPARTATE RECEPTORS
}

\author{
J. LU, ${ }^{a}$ D. GOULA, ${ }^{\text {a }}$ N. SOUSA ${ }^{\text {b }}$ AND \\ O. F. X. ALMEIDA ${ }^{a *}$ \\ aMax Planck Institute of Psychiatry, Kraepelinstrasse 2-10, D-80804 \\ Munich, Germany \\ ${ }^{b}$ Life and Health Science Research Institute, Universidade do Minho, \\ Campus de Gualtar, Braga, 4710-057 Portugal
}

\begin{abstract}
Glutamate receptors have been proposed to mediate the apoptotic actions of glucocorticoids in hippocampal cells. To further analyze the role of glutamate receptors in this process, we pretreated primary hippocampal cells from neonatal (postnatal day 4) rats with antagonists of ionotropic glutamate receptor (iGluR) and metabotropic glutamate receptor (mGluR) antagonists before exposure to the specific glucocorticoid receptor agonist dexamethasone (DEX) at a dose of $1 \mu \mathrm{M}$. Dizocilpine (MK801; a general N-methyl-Daspartic acid [NMDA] receptor antagonist, NMDAR antagonist) and ifenprodil (a specific ligand of the NMDAR 2B subunit, NR2B), were used to block iGluR; (RS)- $\alpha$-ethyl-4-carboxyphenylglycine (E4CPG) and (RS)- $\alpha$-cyclopropyl-4phosphonophenyl-glycine (CPPG) were employed as I/II (E4CPG) and II/III (CPPG) mGluR antagonists. Blockade of iGluR resulted in a significant attenuation of DEX-induced cell death; the finding that ifenprodil exerted a similar potency to MK801 demonstrates the involvement of NR2B receptors in glucocorticoid-induced cell death. Apoptosis accounted for a significant amount of the cell loss observed, as detected by terminal deoxynucleotidyl transferase-mediated dUTP nick-end labeling histochemistry for the in situ labeling of DNA breaks; apoptotic cells were distinguished from necrosis on the basis of morphological criteria, including chromatin condensation, membrane blebbing and presence of apoptotic bodies. Treatment with E4CPG and CPPG completely abolished the apoptotic response to DEX, thus showing the additional contribution of mGluR to the phenomenon. Further, dose-response studies with NMDA revealed that whereas high $(10 \mu \mathrm{M})$ doses of NMDA themselves elicit cytotoxic responses, low (1-5 $\mu \mathrm{M})$ concentrations of NMDA can effectively oppose DEX-induced cell death. Interestingly, the neuroprotective actions of low dose NMDA stimulation were abolished when either synaptic or extrasynaptic NMDA receptors were blocked with MK801 in combination with the
\end{abstract}

*Corresponding author. Tel: +49-89-30622-216; fax: +49-89-30622461.

E-mail address: osa@mpipsykl.mpg.de (O. F. X. Almeida).

Abbreviations: CPPG, $(R S)-\alpha$-cyclopropyl-4-phosphonophenylglycine; DEX, dexamethasone; E4CPG, $(R S)$ - $\alpha$-ethyl-4-carboxyphenylglycine; EBBS, Earle's buffered salt solution; GluR, glutamate receptor; GR, glucocorticoid receptor; iGluR, ionotropic glutamate receptor; mGluR, metabotropic glutamate receptor; MK-801, dizocilpine; MR, mineralocorticoid receptor; NMDA, N-methyl-D-aspartic acid; NMDAR, NMDA receptor; NR2A, NMDA receptor subunit 2A; NR2B, NMDA receptor subunit 2B; $\mathrm{P}$, postnatal day; TUNEL, terminal deoxynucleotidyl transferase-mediated dUTP nick-end labeling.
GABA receptor antagonist bicuculline (synaptic) or ifenprodil (extrasynaptic). In summary, the present data show that both iGluR and mGluR mediate the neurotoxic effects of glucocorticoids on hippocampal cells and that pre-treatment with low doses of NMDA, by acting on synaptic and extrasynaptic receptors, render hippocampal cells less vulnerable to glucocorticoid insults. ( 2003 IBRO. Published by Elsevier Ltd. All rights reserved.

Key words: glucocorticoids, glutamate, NMDA, ionotropic glutamate receptor, metabotropic glutamate receptor, hippocampus.

Glucocorticoids (represented endogenously by cortisol and corticosterone) are hormones secreted by the adrenal cortex in response to stress. Acting through hippocampal receptors (glucocorticoid receptors [GR]), they play an important role in the physiological and behavioral adaptive responses to stress (Sapolsky et al., 2000). On the other hand, there is an abundant literature indicating that excessive glucocorticoid secretion can result in damaging effects on adaptive mechanisms as well as on the viability of structural integrity of neurons in the hippocampus. Notably, activation of GR leads to neuritic atrophy and death of neurons, a phenomenon that has been linked to disorders of mood and cognition as well as neuroendocrine dysregulation (De Kloet et al., 1998; McEwen, 2000; Sapolsky, 2000; Abraham et al., 2001; Sousa and Almeida, 2002). Despite some conflicting reports (Masters et al., 1989; Roy and Sapolsky, 2003), work from our laboratory has demonstrated that apoptosis is at least one of the forms of cell death resulting from exposure to glucocorticoids; that conclusion was made in light of the presence of specific morphological features (see Hassan et al., 1996) and the activation of key pro-apoptotic versus anti-apoptotic genes (Almeida et al., 2000). Several different, although not mutually exclusive, mechanisms have been implicated in these GR-mediated neurodegenerative effects; these include reduced glucose uptake by neurons, increases in the extracellular concentrations of glutamate with concomitant elevations in intracellular $\mathrm{Ca}^{2+}$ levels (Sapolsky, 2000).

Glutamate is the dominant neurotransmitter in the brain, being found in most excitatory synapses. Its actions are mediated by ionotropic glutamate receptors (iGluR) which are directly associated with ligand-gated ionophores permitting $\mathrm{Ca}^{2+}$ influx, and metabotropic glutamate receptors (mGluR); the latter are $\mathrm{G}$ protein-coupled receptors which can activate secondary messengers such as cAMP 
or diacylglycerol and phosphoinositides (Lipton and Rosenberg, 1994; Pin and Duvoisin, 1995). Both types of receptor can activate downstream pathways that determine cell survival or death. Their dichotomous actions appear to result from differences in the duration and magnitude of action and the subsequent levels of intracellular $\mathrm{Ca}^{2+}$. Synaptic $\mathrm{N}$-methyl-D-aspartic acid (NMDA) receptor (NMDAR), which respond to physiological (low dose) NMDAR activation, have been associated with the promotion of cell survival; in contrast, extrasynaptic NMDAR located on the cell body, axon and dendritic spines (Li et al., 1998; Tovar and Westbrook, 1999) have been associated with apoptosis (Hardingham et al., 2002; Riccio and Ginty, 2002). As compared with the synaptic NMDAR, the extrasynaptic NMDAR is characterized by a faster and more extensive rundown of peak current (Li et al., 2002). It is currently believed that while activation of extrasynaptic NMDAR is a rare event under normal conditions, it becomes more common during acute cellular insults or pathological situations when glutamate transporters operate in reverse, thereby increasing extracellular concentrations of glutamate (Rossi et al., 2000).

Gluocorticoids and glutamate receptor (GluR) share an intimate relationship: (i) glucocorticoids can increase hippocampal cell vulnerability to GluR activation (Armanini et al., 1990); (ii) GR activation leads to an up-regulation of the expression of one type of GluR, the ionotropic NMDAR, strongly implicated in neurotoxicity (Weiland et al., 1997); (iii) elevated glucocorticoid levels have been associated with an increase in glutamatergic transmission (Moghaddam et al., 1994) and (iv) glutamate can enhance GR activation (Gursoy et al., 2001). In light of these interactions, and given the neurotoxic potential of each, glutamate and glucocorticoids, the many possibilities for mutual potentiation of each other's effects can be easily appreciated.

Blockade of the NMDAR was previously shown to mediate the inhibitory effects of stress (during which glucocorticoid secretion is increased) on neurogenesis in the hippocampus; this observation provides a clue as to the particular subtype of GluR that may mediate at least some glucocorticoid actions (Gould et al., 1997). The studies described here were designed to provide further insight into the role of GluR in dexamethasone (DEX)-induced cell death in the hippocampus. To do so, we resorted to an in vitro model, treating primary hippocampal cells from postnatal day 4 (P4) rats with ionotropic and metabotropic GluR antagonists, to evaluate the role of each of these receptors in DEX-induced apoptosis. A further objective of this study was to explore the possibility of an additive effect of DEX and NMDA; for this, hippocampal cells were exposed to a range of NMDA concentrations before subsequent treatment with DEX. Finally, the role of extrasynaptic versus synaptic NMDAR in these events was examined with the aid of ifenprodil, a selective antagonist of extrasynaptic NMDA-R, and a combination of MK-801 and bicuculline to block synaptic NMDAR.

\section{EXPERIMENTAL PROCEDURES}

\section{Primary cell culture}

Cultures were prepared from Wistar rats aged 4 days (P4; Charles River, Sulzfeld, Germany), following a protocol previously developed in our laboratory (Crochemore, 2000). Briefly, hippocampal slices were digested using the Papain Dissociation System from Worthington Biochemicals (Lakewood, NJ, USA) and the dissociated cells plated on poly- $d$-lysine-coated glass coverslips at a density of 400 cells $/ \mathrm{mm}^{2}$. Cultures were maintained in Neurobasal A medium to which $2 \%$ B27 supplement, 1 mM Glutamaxl (Invitrogen, Eggenstein, Germany) and $0.1 \mathrm{mg} / \mathrm{ml}$ kanamycin were added (all supplements from Invitrogen). Culture medium was half-renewed every 3 days. Experiments were started 6 days after plating. Immunocytochemical analysis of the cultures revealed that the cultures comprised ca. $90 \%$ neurons (neuronal markers used: NeuN, TuJ1 and doublecortin) and ca. 10\% astro-glial cells (glial fibrillary acidic protein-positive).

\section{Drugs}

DEX, obtained as a freely-soluble sodium salt from Merck (Darmstadt, Germany), was used at a concentration of $1 \mu \mathrm{M}$ in all experiments; DEX treatment was always added to cultures after 3-6 days in vitro for $72 \mathrm{~h}$. In all experiments, the mineralocorticoid receptor (MR) antagonist spironolactone was added $(10 \mu \mathrm{M})$ in order to antagonize interfering effects from low (nanomolar range) MR-activating doses of corticosterone present in the culture medium (Crochemore, 2000). NMDA was obtained from Sigma Chemicals (Deisenhofen, Germany). All other drugs were purchased from Tocris (Bristol, UK). They included bicuculline (used at $50 \mu \mathrm{M}$ ), MK801 (a general NMDAR antagonist; used at $10 \mu \mathrm{M}$ ), ifenprodil (a specific ligand of the NMDAR 2B subunit; used at $10 \mu \mathrm{M})$, and (RS)- $\alpha$-ethyl-4-carboxyphenylglycine (E4CPG) and $(R S)$ - $\alpha$-cyclopropyl-4-phosphonophenyl-glycine (CPPG), antagonists of mGluR I/II and mGluRII/III, respectively (both used at $10 \mu \mathrm{M})$. The precise treatment protocols used in individual experiments are detailed below.

\section{Experiment 1: attenuation of DEX-induced apoptosis by GluR blockade}

Hippocampal cells were pretreated with either MK801, ifenprodil or a combination of CPPG and E4CPG for 15 min before addition of DEX (continued presence of antagonists) for $72 \mathrm{~h}$ after which cultures were analyzed for the incidence of apoptosis.

\section{Experiment 2: dose-dependent effects of NMDA on DEX-induced cell death}

In the first part of this experiment, cells were treated with NMDA for $15 \mathrm{~min}$ at doses between 1 and $10 \mu \mathrm{M}$; assessment of cell death (apoptosis and necrosis) was performed $72 \mathrm{~h}$ later. In order to maximize the NMDA effects, the usual culture medium (supplemented Neurobasal A) was replaced by and added to the cells in $\mathrm{Mg}^{2+}$ free Earle's buffered salt solution (EBSS; Invitrogen) containing $10 \mu \mathrm{M}$ glycine. The treatment schedule for the second part of the experiment was as follows: pre-exposure to NMDA (1-10 $\mu \mathrm{M}$ in $\mathrm{Mg}^{2+}$ free EBSS plus $10 \mu \mathrm{M}$ glycine) for $15 \mathrm{~min}$, followed by a washout step, and addition of DEX ( $1 \mu \mathrm{M}$ in supplemented Neurobasal A) for $72 \mathrm{~h}$. At this point, the cultures were fixed and processed for the detection of apoptosis.

\section{Experiment 3: role of synaptic receptors in NMDA- associated neuroprotection}

After pre-exposure to a mixture of bicuculline and MK801 (50 $\mu \mathrm{M}$ and $10 \mu \mathrm{M}$, both in $\mathrm{Mg}^{2+}$ free EBSS plus $10 \mu \mathrm{M}$ glycine) for 15 min, a washout step, NMDA (1 or $5 \mu \mathrm{M}$ ) was added and incubation 
continued for a further $15 \mathrm{~min}$. A thorough washout step was then performed and cells were subsequently treated with DEX $(1 \mu \mathrm{M}$ in supplemented Neurobasal A) and maintained for $72 \mathrm{~h}$ when they were processed for the detection of apoptosis.

\section{Experiment 4: attenuation of NMDA-induced neuroprotection by ifenprodil}

After pre-exposure to ifenprodil $(10 \mu \mathrm{M})$ and NMDA (1 or $5 \mu \mathrm{M}$ in $\mathrm{Mg}^{2+}$ free EBSS plus $10 \mu \mathrm{M}$ glycine) for $15 \mathrm{~min}$, and a washout step, cultures were then transferred to supplemented Neurobasal A medium containing DEX at a concentration of $1 \mu \mathrm{M}$ for $72 \mathrm{~h}$ before being examined for apoptosis.

\section{Cell death assay}

Cell death was examined in $4 \%$ paraformaldehyde-fixed cells by terminal deoxynucleotidyl transferase-mediated dUTP nick-end labeling (TUNEL) histochemistry or Hoechst 33342 staining. When TUNEL histochemistry was to be performed, permeabilization $(0.1 \%$ Triton $\mathrm{X}-100)$ and peroxidase blocking $\left(1 \% \mathrm{H}_{2} \mathrm{O}_{2}\right)$ steps were carried out before application of the TUNEL assay as previously described (Almeida et al., 2000). Apoptotic cells were characterized by dark brown nuclear staining; only those nuclei showing evidence of DNA fragmentation without plasma membrane damage were taken to be apoptotic cells. Hoechst staining was used in a few cases to confirm TUNEL staining. Fixed cells were incubated with the dye $(1: 1000)$ for 15 min before examination under a fluorescence microscope. Apoptotic versus total cells (\%) were quantified in at least five randomly chosen microscopic fields $\left(0.072 \mathrm{~mm}^{2}\right.$, magnification of $\left.400 \times\right)$ across the long axis of the coverslips on which cells were grown; an average of 1000 cells were sampled on each coverslip and the results shown represent values from six to 10 coverslips per treatment.

\section{Statistical analysis}

All data are depicted as means \pm S.D. and represent the observations from three to five independent experiments, with three to four replicates for each data point. Data were analyzed for statistical significance using ANOVA and appropriate post hoc tests (Student-Newman-Keuls or Kruskal-Wallis multiple comparison procedures) in which $P \leq 0.05$ was set as the minimum level of significance.

\section{RESULTS}

Throughout, TUNEL-positive cells were considered to be apoptotic only if they showed the characteristic morphological features of apoptosis (see Hassan et al., 1996). Under control conditions (no drug treatment), basal rates of apoptosis were $10.9 \pm 1.9 \%$ (TUNEL-positive cells meeting morphological criteria of apoptosis expressed as a percentage of total number of cells; mean \pm S.E.M.). Representative microscopic fields from TUNEL-stained control and DEX-treated cultures are shown in Fig. 1.

\section{Attenuation of DEX-induced apoptosis by GluR blockade (Fig. 2)}

Apoptosis was significantly increased in hippocampal cultures exposed for $72 \mathrm{~h}$ to the GR-specific agonist DEX at a dose of $10^{-6} \mathrm{M}(P<0.05)$; the apoptotic effects of DEX were abrogated by the GR antagonist RU 38486 (mifepristone, $10^{-5} \mathrm{M}$ ), indicating mediation by GR (data not shown). Subsequent experiments involved pretreatment of cells with various GluR antagonists (at $10^{-5} \mathrm{M}$ for $30 \mathrm{~min}$ before the introduction of, and during exposure to, DEX at $10^{-6} \mathrm{M}$ ). Concomitant treatment with the general NMDAR antagonist MK801 or the NR2B-specific antagonist ifenprodil rescued cells from DEX-induced apoptosis $(P<0.01)$ to levels that were not significantly different from those observed under drug-naive conditions. In the absence of DEX, MK801 and ifenprodil did not exert significant effects on the rate of apoptosis in the cultures (data not shown). Application of the mGluR antagonists E4CPG (mGluR I/II) and CPPG (mGluR II/III), while not exerting any effects on their own (data not shown), abolished the apoptotic actions of DEX $(P<0.001)$ and significantly improved basal cell survival $(P<0.05)$, i.e. the protective effects afforded by the mGluR antagonists exceeded those provided by NMDAR blockade $(P<0.01$ or $P<0.001)$.

The results of this experiment therefore conclusively demonstrate that induction of apoptosis by DEX is mediated by GR and, in turn, by iGluR and mGluR.

\section{Dose-dependent effects of NMDA on DEX-induced cell death (Fig. 3)}

In view of the above findings implicating NMDAR involvement in the apoptotic actions of DEX, we first conducted a dose-response study with NMDA. The NMDA was added for $15 \mathrm{~min}$ in $\mathrm{Mg}^{2+}$-free medium containing $10 \mu \mathrm{M}$ glycine. As shown in Fig. 3A, the two lower doses of NMDA (1 and $5 \mu \mathrm{M}$ ) did not influence hippocampal survival, as assessed $72 \mathrm{~h}$ after application of the drug. In contrast, the highest dose tested $(10 \mu \mathrm{M})$ led to a significant increase in cell death $(P<0.05)$. Based on this result as well as reports that GR activation can increase the vulnerability of hippocampal cells to glutamatergic toxicity (Armanini et al., 1990), we subsequently examined whether pre-exposure to NMDA can influence the magnitude of DEX-induced cell death; in these experiments, cells were pre-treated with NMDA and then exposed to DEX (in the absence of NMDA) for $72 \mathrm{~h}$. As shown in Fig. 3B, the highest dose of NMDA $(10 \mu \mathrm{M})$ resulted in cell death but did not potentiate the effects of DEX. On the other hand, and contrary to our predictions, NMDA at one and $5 \mu \mathrm{M}$ was found to significantly attenuate the apoptotic actions of DEX $(P<0.001$ and $P<0.01$ ).

These results demonstrate that low doses of NMDA can counteract the cell death-inducing effects of DEX.

\section{Synaptic receptors mediate the neuroprotective effects of NMDA (Fig. 4)}

Recent evidence suggests that extrasynaptic NMDAR may be responsible for triggering excitotoxicity; in contrast, synaptic NMDAR are thought to activate cell survival-promoting signaling cascades (Hardingham et al., 2002). In contrast to NMDA receptor subunit $2 A$ (NR2A) subunits which are mainly found in synaptic NMDAR, NMDA receptor subunit 2B (NR2B) predominate in extrasynaptic NMDAR (Tovar and Westbrook, 1999). Because of this, and the fact that we observed that DEXinduced apoptosis could be attenuated by antagonism of the NR2B subunit with ifenprodil (Fig. 2), it was of inter- 

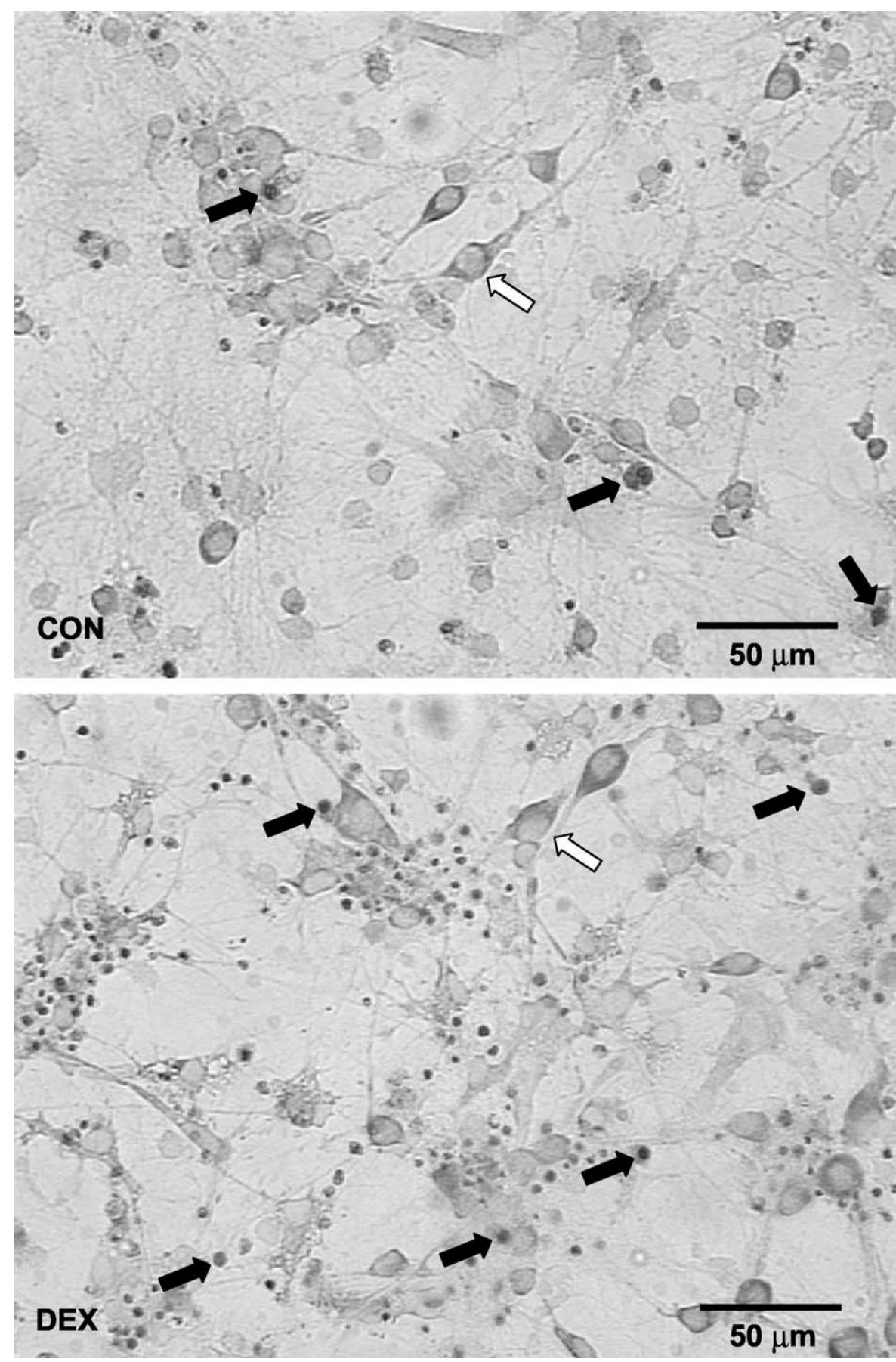

Fig. 1. DEX increases apoptosis in primary hippocampal cell cultures. Photomicrographs show TUNEL-staining in control (upper panel) and DEX-treated (lower panel) cells. Examples of TUNEL-positive cells displaying some of the morphological features used to designate apoptotic cells in this study (e.g. shrunken cell body or apoptotic bodies) are marked with black arrows. Note that the relative number of apoptotic versus healthy cells (white arrows) is increased after exposure to DEX (lower panel).

est to examine the role of extrasynaptic NMDAR in our paradigm. Following a recently described experimental paradigm (Hardingham et al., 2002), we applied the GABA receptor antagonist bicuculline $(1 \mu \mathrm{M})$ together with MK801 (5 $\mu \mathrm{M})$ in order to subsequently be able to activate extrasynaptic NMDAR selectively. This treat- ment paradigm abolished the ability of the low doses of NMDA ( 1 and $5 \mu \mathrm{M})$ to counteract the apoptosis-inducing effects of DEX $(P<0.001$ and $P<0.05)$.

These findings conform with the view that synaptic NMDAR play a permissive role in the neuroprotective actions of low doses of NMDA. 

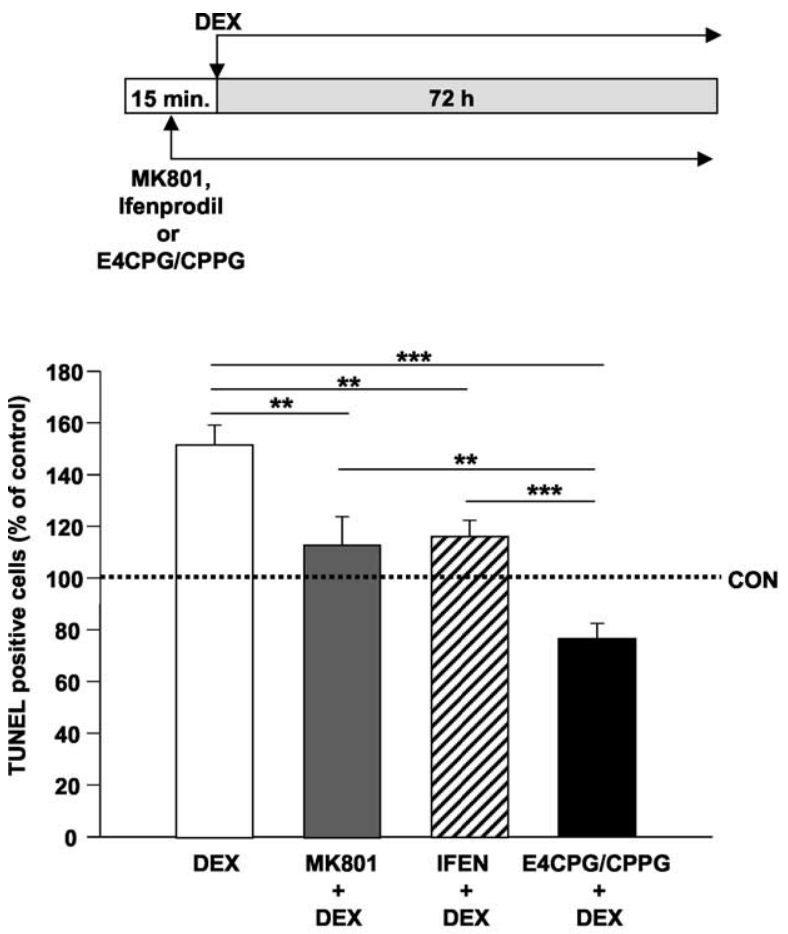

Fig. 2. Attenuation of DEX-induced apoptosis by GluR blockade. Treatment of hippocampal cultures with MK801 (NMDAR antagonist), ifenprodil (IFEN; selective NR2B subunit antagonist) and E4CPPG/ CPPG (antagonists of mGluRI/II and mGluRII/III, respectively) for 15 min before and during application of DEX $(1 \mu \mathrm{M})$ resulted in a significant reduction in DEX-induced apoptosis, as measured by TUNEL histochemistry. All of the antagonists were used at $10 \mu \mathrm{M}$. ${ }^{* *}$ and ${ }^{* * *}$ indicate $P<0.01$ and $<0.001$, respectively. Results represent means \pm S.D. from five experiments, with three replicates for each data point.

\section{Ifenprodil attenuates low dose NMDA-induced neuroprotection (Fig. 5)}

NR2B are predominantly expressed at extrasynaptic sites which have been associated with neurotoxicity (Hardingham et al., 2002). As mentioned, ifenprodil is a selective inhibitor of the NR2B subunit of the NMDAR (Gotti et al., 1988 ) and has proven neuroprotective efficacy in animal models of degeneration (Kemp and McKernan, 2002). The results depicted in Fig. 2 show that ifenprodil can reduce the cytotoxic effects of DEX. Since the results of the previous experiment (Fig. 4) indicated that synaptic receptors mediate the protective effects of low doses of NMDA, the question arose as to the impact of NR2B extrasynaptic receptor antagonism on DEX-induced cell death. Because ifenprodil is an activity-dependent NR2B antagonist, cells were pre-treated with NMDA (1 and $5 \mu \mathrm{M})$ and ifenprodil $(10 \mu \mathrm{M})$ for $15 \mathrm{~min}$, before wash-out and exposure to DEX $(1 \mu \mathrm{M})$ for $72 \mathrm{~h}$. Contrary to our prediction, hippocampal cultures treated according to this paradigm displayed more apoptosis than those exposed only to the NMDA pulse followed by DEX $(P<0.01$ and $P<0.05)$. Thus, these observations indicate that transient blockade of NR2B can prevent low doses of NMDA from exerting protective actions against DEX-induced apoptosis.
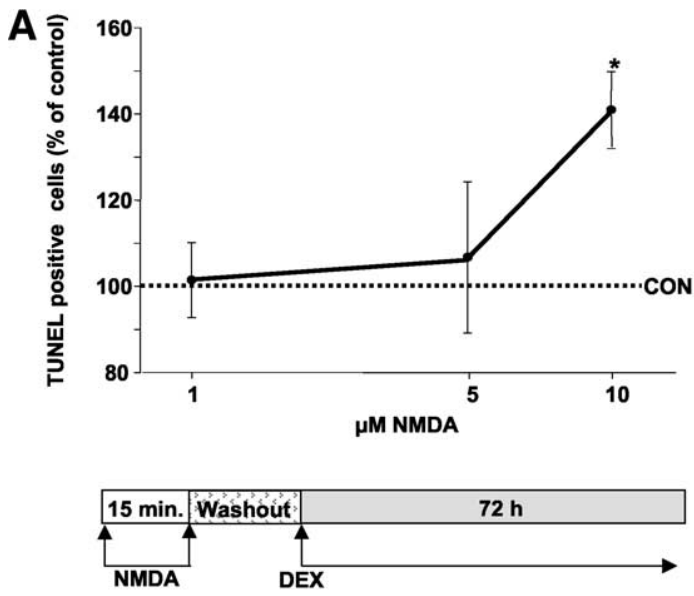

B

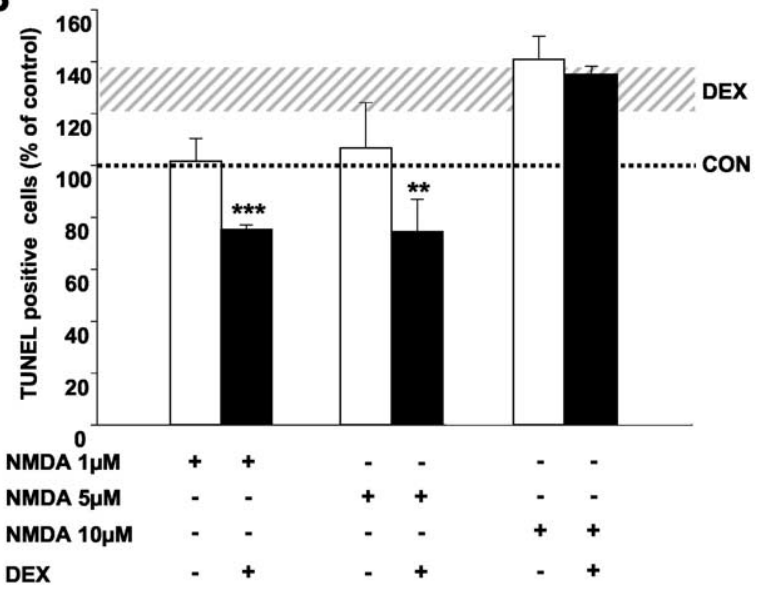

Fig. 3. Dose-dependent effects of NMDA on DEX-induced cell death. Cell death was assessed after treatment of cultures for 15 min with NMDA ranging from 1 to $10 \mu \mathrm{M}$. A. Dose-response curve showing that 1 and $5 \mu \mathrm{M}$ NMDA did not have affect on cell survival, whereas $10 \mu \mathrm{M}$ of the drug significantly stimulated cell death. Note that data shown refer only to counts of TUNEL-positive cells, although after exposure to $10 \mu \mathrm{M}$ NMDA, there was an increase in the number of cells showing signs of necrosis. B. Demonstration that pretreatment with low, subtoxic doses of NMDA ( 1 and $5 \mu \mathrm{M}$ ) can attenuate DEX-induced apoptosis. The stippled area represents the effects of treatment with $1 \mu \mathrm{M}$ of DEX for $72 \mathrm{~h}$. All values shown are means \pm S.D., derived from five experiments (in which each data point was replicated four times). *** and ${ }^{* * *}$ indicate significant differences where $P<0.05,<0.01$ and $<0.001$, respectively.

\section{DISCUSSION}

Glucocorticoids fulfill several important functions in the hippocampus, including cognition, mood and neuroendocrine regulation. Nevertheless, high levels of both endogenous and therapeutic glucocorticoids can affect hippocampal function deleteriously. These undesired effects have been proposed to result from either neuronal atrophy and, in extreme cases, neuronal cell death of certain principal cells of the hippocampus (for review, see Sousa and Almeida, 2002).

Glucocorticoids can exert rapid, transient effects on neuronal excitability involving increased cytosolic concentrations of $\mathrm{Ca}^{2+}$ (Nair et al., 1998). However, glucocorticoid actions are best known to be mediated through GR which are transcription factors and our group has previ- 

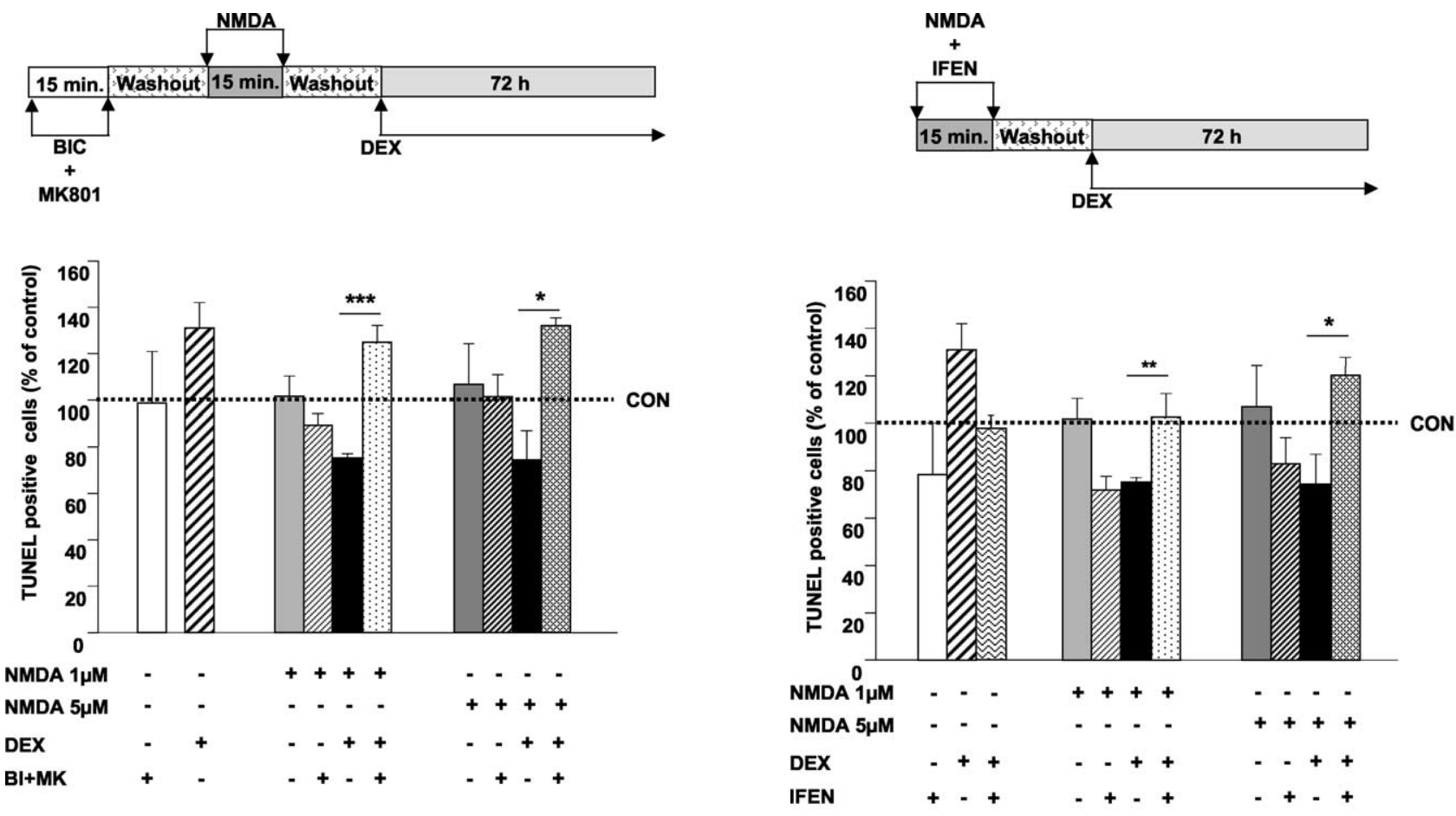

Fig. 4. Synaptic receptors mediate the neuroprotective effects of NMDA. Synaptic NMDAR were blocked by initially exposing hippocampal cultures to the GABA antagonist bicuculline $(50 \mu \mathrm{M})$ and the activity-dependent NMDAR antagonist MK801 $(10 \mu M)$. Subsequently, cells were treated with NMDA ( 1 or $5 \mu \mathrm{M} ; 15 \mathrm{~min}$ ), washed and exposed to DEX $(1 \mu \mathrm{M})$ for a further $72 \mathrm{~h}$ when apoptosis was measured. Results (means \pm S.D. from four experiments, with four replicates for each data point) show that blockade of synaptic NMDAR prevents low doses of NMDA to counteract the apoptotic actions of DEX. ${ }^{*}$ and ${ }^{* * *}$ indicate significant differences where $P<0.05$ and 0.001 , respectively.

ously elucidated some of the cell death-related molecular pathways triggered by exposure to the potent GR agonist DEX (Almeida et al., 2000). Thus, glucocorticoid effects on hippocampal structure and function do not necessarily result from one exclusive mechanism (electrophysiological versus genomic) but rather may occur as a result of integrated signals arising from both the cell membrane and transcriptional activity. For example, by repressing the transcription of $\mathrm{Ca}^{2+}$ channel and $\mathrm{Ca}^{2+}$ extrusion pump genes (Bhargava et al., 2000), glucocorticoids contribute to long-term alterations in the dynamics of intracellular $\mathrm{Ca}^{2+}$ levels, including those originating at the plasma membrane (Kerr et al., 1992; Elliott and Sapolsky, 1993; Nair et al., 1998; Bhargava et al., 2000).

Exaggerated and chronic elevations in intracellular $\mathrm{Ca}^{2+}$ accompany glutamatergic excitotoxicity (Choi, 1991; Coyle and Puttfarcken, 1993) and have also been proposed to at least partially underlie the neurotoxic effects of glucocorticoids (Joëls, 2001). Increases in cytosolic $\mathrm{Ca}^{2+}$ concentrations result from the activation of both iGluR and mGluR, albeit through different mechanisms: iGluR stimulate the influx of $\mathrm{Ca}^{2+}$ from the extracellular space, whereas mGluR mobilize $\mathrm{Ca}^{2+}$ from intracellular reser-

Fig. 5. Ifenprodil attenuates low dose NMDA-induced neuroprotection. Pharmacological blockade of the NR2B subunit of the NMDAR was achieved by pre-incubating cells with ifenprodil (IFEN, $10 \mu \mathrm{M}$ ). Subsequently, the ability of low doses of NMDA (1 or $5 \mu \mathrm{M})$ to protect against the apoptotic effects of DEX $(1 \mu \mathrm{M} ; 72 \mathrm{~h})$ was examined. The data (means \pm S.D. derived from three experiments, with three replicates for each data point) show that the protective effects of NMDA are markedly attenuated when NR2B-containing NMDAR are rendered non-functional by IFEN. * and ${ }^{* *}$ indicate significant differences where $P<0.05$ and $<0.01$, respectively.

voirs (Maiese et al., 1999; Otani et al., 2002). Glucocorticoids are known to increase NMDAR expression and glutamate synthesis and extracellular accumulation (Weiland et al., 1997; Moghaddam et al., 1994), and to potentiate glutamate-induced cell death (Goodman et al., 1996; Behl et al., 1997; Abraham et al., 2001; Johnson et al., 2002). To date, however, earlier suggestions that glutamatergic mechanisms may play an intermediary role in glucocorticoid-induced cell death have remained largely unsupported by firm experimental evidence. The data presented in this paper fill that gap by demonstrating that iGluR (here, only the NMDAR type was studied) and mGluR mediate at least some of the apoptotic effects of DEX in primary hippocampal cultures. With respect to the involvement of iGluR, our data show that general blockade of NMDAR with MK801 significantly attenuates DEX-triggered cell death (Fig. 2).

GluR are well-recognized triggers of neuronal cell death and may occur either acutely upon activation or after a period of delay (Choi, 1991). These two forms of neuronal death are distinguishable on the basis of their morphological characteristics and ionic dependence. The rapidonset form is necrotic in nature, characterized by cell swelling, intact nuclei with diffuse nucleoplasm, disrupted cell membrane and ultimate cell lysis. In contrast, the delayed 
form is $\mathrm{Ca}^{2+}$-dependent, and is accompanied by cell shrinkage, membrane blebbing and nuclear condensation and fragmentation (karyoklasis); all of the latter features are typical of apoptosis (Choi, 1991). In the present work, the dominant form of cell death observed following treatment of hippocampal cells with both NMDA and DEX was of the apoptotic type.

The NMDAR has been the most intensely studied GluR, especially in the context of neurotoxicity. NMDAR are heteromeric in nature; they consist of a common NMDA receptor subunit 1 and one or more NR2 subunits (NR2A-D), whose insertion in the NMDAR complex varies during development and maturity of synapses ( $\mathrm{Li}$ et al., 1998; Stocca and Vicini, 1998; Tovar and Westbrook, 1999). For example, it is known that whereas NR2A is predominantly found in NMDAR located at the synapse, NR2B are localized almost exclusively in NMDAR at extrasynaptic (non-synaptic) sites. An important concept that has emerged from recent studies is that synaptic NMDAR can initiate neuroprotective mechanisms; in contrast, activation of extrasynaptic NMDAR results in cell death (Hardingham et al., 2002). The present experiments demonstrate that selective inhibition of NR2B with ifenprodil results in a suppression of DEX-induced apoptosis (Fig. 2); this finding is consistent with the documented efficacy of ifenprodil in retarding cell death in various animal models of neurodegenerative disease (for review see Chenard and Menniti, 1999).

Previous work which showed that GluR stimulation can result in excitotoxicity and that the latter can be amplified by pre-treatment with glucocorticoids (Goodman et al., 1996; Behl et al., 1997; Abraham et al., 2001; Johnson et al., 2002) prompted us to examine the effects of NMDA pre-treatment on DEX-induced apoptosis. To do this, we treated hippocampal cultures with NMDA at doses ranging from 1 to $10 \mu \mathrm{M}$ for a brief period ( $15 \mathrm{~min}$ ) before exposure to DEX $(1 \mu \mathrm{M})$ for $72 \mathrm{~h}$. We observed a complete abolition of the apoptotic actions of DEX when cells were preexposed to NDMA at 1 and $5 \mu \mathrm{M}$; at a dose of $10 \mu \mathrm{M}$, NMDA resulted in overt necrosis (Fig. 3). Subtoxic concentrations of NMDA are indeed known to elicit neurotrophic and anti-apoptotic mechanisms in neurons (Marini et al., 1998; Resink et al., 1996; Brandoli et al., 1998); moreover, one of the implicated neurotrophins, brain-derived nerve growth factor, has been found to stimulate (pro-survival) NR2A subunit expression and to suppress NR2B (deathpromoting) expression (Glazner and Mattson, 2000). Because our experimental paradigm involved chronic exposure to DEX, it is pertinent to mention a study which showed that GR activation leads to an increase in NR2B subunit gene expression with a concomitant decrease in the expression of the gene encoding NR2A subunit (Nair et al., 1998).

As noted above, NMDAR including the death-promoting NR2B subunit are predominantly localized at extrasynaptic sites; in contrast those comprising the pro-survival NR2A subunit have a synaptic location (Riccio and Ginty, 2002). Since the appearance of NR2A- and NR2B-containing NMDAR is correlated with the ontogeny of synapses
(Tovar and Westbrook, 1999; Li et al., 1998; Stocca and Vicini, 1998), it is pertinent to note that although the cultures used for the present studies were relatively young (experiments carried out after 6 days in vitro), cell-cell interactions were abundantly evident at the light microscopic level. In order to distinguish between synaptic and extrasynaptic NMDAR in the mediation of the protective actions of low doses of NMDA against DEX-stimulated apoptosis, we adopted the recently described elegant pharmacological paradigm described by Hardingham et al. (2002). Briefly, the paradigm which consists of pre-treating (15 min) hippocampal cultures with the GABA antagonist bicuculline (to activate synaptic GluR) and MK801 (to block active NMDAR) prevents NMDA activation of neuroprotective signaling cascades, leaving only extrasynaptic NR2Bcontaining NMDAR available for NMDA binding. Cultures pre-treated in this way were subsequently exposed to 1 or $5 \mu \mathrm{M}$ NMDA and DEX, after which they were analyzed for apoptosis. The observation that the bicuculline/MK801 pre-treatment abrogated the ability of NMDA to oppose the apoptotic actions of DEX (Fig. 4) is consistent with a synaptic site of NMDA-induced neuroprotection (cf. Hardingham et al., 2002).

In an experiment to examine the impact of NR2B subunit-containing NMDAR blockade on the neuroprotection afforded by subtoxic NMDA doses against DEX-elicited apoptosis, NR2B blockade was achieved by pre-treating cells with NMDA and ifenprodil. It was reasoned that this experimental design would ensure binding of ifenprodil, an activity-dependent antagonist, to extrasynaptic receptors and, at the same time, permit (or even enhance) the activity of synaptic NMDAR. Contrary to expectations, we observed that the NR2B-blocking procedure led to an amplification of DEX-induced apoptosis (Fig. 5). Only speculative explanations can be offered for this finding at present. Assuming similar affinities of NMDA for NR2A and NR2B, and that neuroprotective NR2A are predominantly occupied under basal conditions, a tenable explanation is that, as extracellular glutamate concentrations increase, neuronal fate is balanced by NR2A versus NR2B activity. Also, since the NMDA/ifenprodil pre-treatment was transient (15 min), it could be that the prolonged exposure to DEX resulted in increased sensitivity and/or up-regulation of the synthesis of death-promoting NR2B receptors, or equally, a down-regulation of pro-survival NR2A receptors; the likelihood of such a mechanism is supported by the observation that extended exposure to ifenprodil abrogated the neurotoxic actions of DEX (Fig. 2). In this context, it should be noted that the GR is a potent transcriptional factor. Thus, another plausible explanation would be that by employing transcriptional mechanisms to elevate glutamate synthesis (Ábrahám et al., 1996), DEX would effectively make more neurotoxic glutamate available for activating NR2 subunit NMDAR, thus positively driving a vicious circle. Further studies are required to clarify these issues.

A role for mGluR was demonstrated by the finding that E4CPG and CPPG, selective antagonists of $\mathrm{mGluR} \mathrm{I/II}$ and II/III, respectively, can rescue hippocampal cells from 
DEX-induced apoptosis; strikingly, it was observed that mGluR antagonism can also improve neuronal survival under basal conditions (Fig. 2). In general, the manifestation of mGluR-mediated actions are slow and involve gene activation. Type I mGluR have been associated with neuronal death (Snyder et al., 2001; Allen et al., 2001; Miskevich et al., 2002; Heidinger et al., 2002) while Type II/II mGluR have been shown to contribute to neuronal survival. The present results, using a cocktail of relatively non-selective antagonists because of the unavailability of more receptor type-specific drugs are interesting: they suggest the involvement of either complex regulatory interactions between the various mGluR or the up-regulation of neurotoxic type I mGluR by DEX.

The present paper represents the first attempt to understand the mechanistic and functional nature of interactions between GluR and glucocorticoids. Its results demonstrate that the apoptotic actions of DEX are at least partly mediated by GluR of the NMDA and metabotropic types. In addition, the results reported herein show that low doses of NMDA, acting via synaptic NMDAR can effectively block hippocampal cell death induced by DEX. Last, this work indicates that glucocorticoids can cause apoptosis in hippocampal cells by triggering rapid (NMDAR-mediated) as well as slow (mGluR- or GR-mediated) responses, and that the final outcome of glucocorticoid treatment on hippocampal cell survival depends on the convergence and integration of transcriptional signals (e.g. GluR and agonist availability; regulation of apoptosis-related genes) and signals originating at the cell membrane (e.g. $\mathrm{Ca}^{2+}$ conductance). Although the present findings are consistent with previous findings, it should be noted that the present experiments were carried out on cells obtained from neonatal hippocampal tissue; therefore, the mechanisms described here do not necessarily apply to the adult hippocampus which has been the focus of the majority of in vivo studies of the neurotoxic actions of glucocorticoids. A second caveat concerns the fact that the serum-free medium used for the cell cultures favored the survival of neurons rather than glia (neuronal-glial ratio approximately $10: 1$ versus $1: 10$ in vivo). Since astrocytic glutamate transporters are important for maintaining low extracellular glutamate concentrations (Nedergaard et al., 2002), the results obtained here more likely represent an extreme situation rather the physiological norm. In this context, it is also important to remember that the dose of DEX $(1 \mu \mathrm{M})$ used in these in vitro experiments is high in relation to the nanomolar concentrations of bioavailable corticosterone that brain neurons are exposed to (Linthorst et al., 2000). Therefore, caution is required in directly extrapolating the present observations to the situation in the organism.

Acknowledgements-We thank Dr. Christophe Crochemore for help with the establishment of the primary hippocampal cultures. Part of this work was supported by a Personnel Exchange Acções Integradas Luso-Alemãs grant from the German Academic Exchange Service, The Portuguese Rectors' Conference and the Portuguese Institute for International Co-operation in Science and
Technology (314/Al-p-dr). The authors are grateful to the two anonymous reviewers for their constructive comments.

\section{REFERENCES}

Abraham IM, Harkany T, Horvath KM, Luiten PG (2001) Action of glucocorticoids on survival of nerve cells: promoting neurodegeneration or neuroprotection? J Neuroendocrinol 13:749-760.

Ábrahám I, Juhász G, Kékesi KA, Kovács KJ (1996) Effect of intrahippocampal dexamethasone on the levels of amino acid transmitters and neuronal excitability. Brain Res 733:56-63.

Allen JW, Vicini S, Faden Al (2001) Exacerbation of neuronal cell death by activation of group I metabotropic glutamate receptors: role of NMDA receptors and arachidonic acid release. Exp Neurol 169:449-460.

Almeida OFX, Condé GL, Crochemore C, Demeneix BA, Fischer D, Hassan AH, Meyer M, Holsboer F, Michaelidis TM (2000) Subtle shifts in the ratio between pro- and antiapoptotic molecules after activation of corticosteroid receptors decide neuronal fate. FASEB J 14:779-790.

Armanini MP, Hutchins C, Stein BA, Sapolsky RM (1990) Glucocorticoid endangerment of hippocampal neurons is NMDA-receptor dependent. Brain Res 532:7-12.

Behl C, Lezoualc'h F, Trapp T, Widmann M, Skutella T, Holsboer F (1997) Glucocorticoids enhance oxidative stress-induced cell death in hippocampal neurons in vitro. Endocrinology 138:101-106.

Bhargava A, Meijer OC, Dallman MF, Pearce D (2000) Plasma membrane calcium pump isoform 1 gene expression is repressed by corticosterone and stress in rat hippocampus. J Neurosci 20:31293138.

Brandoli C, Sanna A, De Bernardi MA, Follesa P, Brooker G, Mocchetti I (1998) Brain-derived neurotrophic factor and basic fibroblast growth factor downregulate NMDA receptor function in cerebellar granule cells. J Neurosci 18:7953-7961.

Chenard BL, Menniti FS (1999) Antagonists selective for NMDA receptors containing the NR2B subunit. Curr Pharm Des 5:381-404.

Choi DW (1991) Excitotoxicity on cultured cortical neurons. In: Glutamate, cell death and memory (Ascher P, Christen Y, Choi DW, eds), pp 125-136. Berlin: Springer-Verlag.

Coyle JT, Puttfarcken P (1993) Oxidative stress, glutamate, and neurodegenerative disorders. Science 262:689-695.

Crochemore, C (2000) Molecular mechanisms underlying corticosteroid influences on neural cell survival. PhD Thesis, Louis Pasteur University, Strasbourg, France.

De Kloet ER, Vreugdenhil E, Oitzl MS, Joels M (1998) Brain corticosteroid receptor balance in health and disease. Endocrinol Rev 19:269-301.

Elliott EM, Sapolsky RM (1993) Corticosterone impairs hippocampal neuronal calcium regulation-possible mediating mechanisms. Brain Res 602:84-90.

Glazner GW, Mattson MP (2000) Differential effects of BDNG, ADNF9, and TNFalpha on levels of NMDA receptor subunits, calcium homeostasis, and neuronal vulnerability to excitotoxicity . Exp Neurol 161:442-452.

Goodman Y, Bruce AJ, Cheng B, Mattson MP (1996) Estrogens attenuate and corticosterone exacerbates excitotoxicity, oxidative injury, and amyloid beta-peptide toxicity in hippocampal neurons. J Neurochem 66:1836-1844.

Gotti B, Duverger D, Bertin J, Carter C, Dupont R, Frost J, Gaudilliere B, MacKenzie ET, Rousseau J, Scatton B, et al (1988) Ifenprodil and SL 82.0715 as cerebral anti-ischemic agents: I. Evidence for efficacy in models of focal cerebral ischemia. J Pharmacol Exp Ther 247:1211-1221.

Gould E, McEwen BS, Tanapat P, Galea LA, Fuchs E (1997) Neurogenesis in the dentate gyrus of the adult tree shrew is regulated by psychosocial stress and NMDA receptor activation. J Neurosci 17:2492-2498.

Gursoy E, Cardounel A, Kalimi M (2001) Pregnenolone protects 
mouse hippocampal (HT-22) cells against glutamate and amyloid beta protein toxicity. Neurochem Res 26:15-21.

Hardingham GE, Fukunaga Y, Bading H (2002) Extrasynaptic NMDARs oppose synaptic NMDARs by triggering CREB shut-off and cell death pathways. Nat Neurosci 5:405-414.

Hassan AH, von Rosenstiel P, Patchev VK, Holsboer F, Almeida OFX (1996) Exacerbation of apoptosis in the dentate gyrus of the aged rat by dexamethasone and the protective role of corticosterone. Exp Neurol 140:43-52.

Heidinger V, Manzerra P, Wang XQ, Strasser U, Yu SP, Choi DW, Behrens MM (2002) Metabotropic glutamate receptor 1-induced upregulation of NMDA receptor current: mediation through the Pyk2/Src-family kinase pathway in cortical neurons. J Neurosci 22:5452-5461.

Joëls M (2001) Corticosteroid actions in the hippocampus. J Neuroendocrinol 13:657-669.

Johnson EA, O'Callaghan JP, Miller DB (2002) Chronic treatment with supraphysiological levels of corticosterone enhances D-MDMAinduced dopaminergic neurotoxicity in the C57BL/6J female mouse. Brain Res 933:130-138.

Kemp JA, McKernan RM (2002) NMDA receptor pathways as drug targets. Nat Neurosci 5 Suppl.1039-1042.

Kerr DS, Campbell LW, Thibault O, Landfield PW (1992) Hippocampal glucocorticoid receptor activation enhances voltage-dependent $\mathrm{Ca}^{2+}$ conductances: relevance to brain aging. Proc Natl Acad Sci USA 89:8527-8531.

Li B, Chen N, Luo T, Otsu Y, Murphy TH, Raymond LA (2002) Differential regulation of synaptic and extra-synaptic NMDA receptors. Nat Neurosci 5:833-834.

Li JH, Wang YH, Wolfe BB, Krueger KE, Corsi L, Stocca G, Vicini S (1998) Developmental changes in localization of NMDA receptor subunits in primary cultures of cortical neurons. Eur $\mathrm{J}$ Neurosci 10:1704-1715

Linthorst ACE, Flachskamm C, Barden N, Holsboer F, Reul JMHM (2000) Glucocorticoid receptor impairment alters CNS responses to a psychological stressor: an in vivo microdialysis study in transgenic mice. Eur J Neurosci 12:283-291.

Lipton SA, Rosenberg PA (1994) Excitatory amino acids as a final common pathway for neurologic disorders. N Engl J Med 330:613622.

Maiese K, Ahmad I, TenBroeke M, Gallant J (1999) Metabotropic glutamate receptor subtypes independently modulate neuronal intracellular calcium. J Neurosci Res 55:472-485.

Marini AM, Rabin SJ, Lipsky RH, Mocchetti I (1998) Activity-dependent release of brain-derived neurotrophic factor underlies the neuroprotective effect of $N$-methyl-D-aspartate. J Biol Chem 273:2939429399.

Masters JN, Finch CE, Sapolsky RM (1989) Glucocorticoid endangerment of hippocampal neurons does not involve deoxyribonucleic acid cleavage. Endocrinology 124:3083-3088.

McEwen BS (2000) The neurobiology of stress: from serendipity to clinical relevance. Brain Res 886:172-189.
Miskevich F, Lu W, Lin SY, Constantine-Paton M (2002) Interaction between metabotropic and NMDA subtypes of glutamate receptors in sprout suppression at young synapses. J Neurosci 22:226-238.

Moghaddam B, Bolinao ML, Stein-Behrens B, Sapolsky R (1994) Glucocorticoids mediate the stress-induced extracellular accumulation of glutamate. Brain Res 655:251-254.

Nair SM, Werkman TR, Craig J, Finnell R, Joëls M, Eberwine JH (1998) Corticosteroid regulation of ion channel conductances and mRNA levels in individual hippocampal CA1 neurons. J Neurosci 18:2685-2696.

Nedergaard M, Takano T, Hansen AJ (2002) Beyond the role of glutamate as a neurotransmitter. Nat Rev Neurosci 3:748-755.

Otani S, Daniel H, Takita M, Crepel F (2002) Long-term depression induced by postsynaptic group II metabotropic glutamate receptors linked to phospholipase $C$ and intracellular calcium rises in rat prefrontal cortex. J Neurosci 22:3434-3444.

Pin JP, Duvoisin R (1995) The metabotropic glutamate receptors: structure and functions. Neuropharmacology 34:1-26.

Resink A, Villa M, Benke D, Hidaka H, Mohler H, Balazs R (1996) Characterization of agonist-induced down-regulation of NMDA receptors in cerebellar granule cell cultures. J Neurochem 66:369377.

Riccio A, Ginty DD (2002) What a privilege to reside at the synapse: NMDA receptor signaling to CREB. Nat Neurosci 5:389-390.

Rossi DJ, Oshima T, Attwell D (2000) Glutamate release in severe brain ischaemia is mainly by reversed uptake. Nature 403:316-321.

Roy M, Sapolsky RM (2003) The exacerbation of hippocampal excitotoxicity by glucocorticoids is not mediated by apoptosis. Neuroendocrinology 77:24-31.

Sapolsky RM (2000) The possibility of neurotoxicity in the hippocampus in major depression: a primer on neuron death. Biol Psychiatry 48:755-765.

Sapolsky RM, Romero LM, Munck AU (2000) How do glucocorticoids influence stress responses? integrating permissive, suppressive, stimulatory, and preparative actions. Endocr Rev 21:55-89.

Snyder EM, Philpot BD, Huber KM, Dong X, Fallon JR, Bear MF (2001) Internalization of ionotropic glutamate receptors in response to mGluR activation. Nat Neurosci 4:1079-1085.

Sousa N, Almeida OFX (2002) Corticosteroids: sculptors of the hippocampal formation. Rev Neurosci 13:59-84.

Stocca G, Vicini S (1998) Increased contribution of NR2A subunit to synaptic NMDA receptors in developing rat cortical neurons. J Physiol 507 Pt 113-24.

Tovar KR, Westbrook GL (1999) The incorporation of NMDA receptors with a distinct subunit composition at nascent hippocampal synapses in vitro. J Neurosci 19:4180-4188.

Weiland NG, Orchinik M, Tanapat P (1997) Chronic corticosterone treatment induces parallel changes in $\mathrm{N}$-methyl-D-aspartate receptor subunit messenger RNA levels and antagonist binding sites in the hippocampus. Neuroscience 78:653-662. 